\title{
Cystoid macular edema after cataract surgery in a patient with previous severe iritis following argon laser peripheral iridoplasty
}

This article was published in the following Dove Press journal:

Clinical Ophthalmology

16 April 201 I

Number of times this article has been viewed

\author{
Alessandro Bagnis' \\ Sergio Claudio Saccà ${ }^{2}$ \\ Michele lester ${ }^{\prime}$ \\ Carlo Enrico Traverso' \\ 'Centro di Ricerca Clinica e \\ Laboratorio per il Glaucoma e la \\ Cornea, Clinica Oculistica Di NOG, \\ University of Genova, ${ }^{2}$ Division of \\ Ophthalmology, St. Martino Hospital, \\ Genova, Italy
}

\begin{abstract}
This report describes a patient who had exaggerated responses to different inflammatory stimuli represented by laser and incisional surgery, respectively. These separate episodes should have a common link represented by a genetic predisposition to abnormal release of proinflammatory mediators within the eye. This 51-year old Hispanic woman showed a narrow iridocorneal angle with plateau iris configuration. Nd-YAG laser peripheral iridotomy was successfully performed to both eyes. No substantial changes in the iridotrabecular angle occurred despite patent iridotomies, thus confirming the diagnosis of plateau iris configuration. Argon laser iridoplasty was then performed to the right eye, while the left eye was scheduled for a later session. A severe inflammatory reaction within the anterior chamber developed after tapering of a one-week course of steroid therapy. Phacoemulsification of the lens was performed some months later when no signs of inflammation were detectable; no intraoperative complications occurred during surgery and an intraocular lens was placed. Cystoid macular edema developed four weeks after surgery despite no apparent risk factors, and resolved completely after antiinflammatory medical therapy. Based on this case report, the unusual occurrence of severe iritis after laser treatment should be regarded as a risk factor for any other incisional or nonincisional procedures because it might indicate that the patient's ocular tissues are prone to release of abnormally elevated proinflammatory mediators. Although further studies are needed to confirm this predisposition, prophylactic adjunctive topical nonsteroidal anti-inflammatory drug administration after cataract surgery should be considered in such cases in order to prevent potentially sight-threatening conditions.
\end{abstract}

Keywords: cystoid macular edema, inflammation, laser surgery, plateau iris configuration

\section{Introduction}

This report describes a patient who had exaggerated responses to inflammatory stimuli. Argon laser peripheral iridoplasty (ALPI) is considered a safe procedure for the management of plateau iris configuration. ${ }^{1} \mathrm{~A}$ well recognized cause of primary angle-closure glaucoma, plateau iris configuration is defined anatomically as a narrow or closed angle, as determined by gonioscopy, in the presence of a flat iris plane and a normaldepth anterior chamber. ${ }^{2}$ This condition is the result of variations in iris and ciliary body anatomy that bring the peripheral iris into contact with the trabecular meshwork. ${ }^{3}$ Almost all eyes undergoing ALPI develop a mild iritis, ${ }^{4}$ which is usually well controlled by topical steroids administered during the 4-7 days following the procedure.

Cystoid macular edema (CME) is a well recognized cause of decreased visual acuity after cataract surgery and its etiology is not fully understood. ${ }^{5}$ Different factors, such as surgical complications (eg, posterior capsule tear, vitreous loss), systemic conditions 
(eg, diabetes), age, and drugs (eg, latanoprost) have been suggested to contribute to its pathogenesis. ${ }^{6-8}$ Patients with uveitis are known to be at higher risk of CME after cataract surgery, and inflammation seems to play a pivotal role in its development. ${ }^{9,10}$

\section{Case report}

A 51-year old Hispanic woman was referred to our practice with a diagnosis of "occludable angle". She denied any systemic disorder, except for mild systemic hypertension, and the history was negative for eye diseases or treatments. The visual acuity was 1.0 in both eyes with a refraction of $+0.50 \mathrm{sph}$ OU. Anterior segment examination showed thinlooking peripheral anterior chambers with regular pupils reacting to light and dark pigmented irises. Gonioscopy revealed bilateral narrow angles throughout the entire circumference, with a plateau configuration appreciable in $270^{\circ}$ of the circumference and no peripheral anterior synechiae (PAS). Nd-YAG laser peripheral iridotomy was successfully performed to both eyes. At a one-week follow-up visit, gonioscopy did not reveal any important changes in the iridotrabecular angle configuration, thus confirming the diagnosis of plateau iris configuration. Using the central nonmirrored part of a Goldman lens, ALPI was performed to the right eye by placing 32 argon laser burns ( $500 \mu \mathrm{m}$ spot size, $500 \mathrm{msec}$ duration, $350 \mathrm{~mW}$ power) circumferentially at the periphery of the iris. One week after discontinuation of a six-day course of topical dexamethasone $0.1 \%$ four times daily, slit lamp examination revealed a severe inflammatory reaction within the anterior chamber, a myotic pupil nonreactive to light, with two posterior synechiae and an intraocular pressure (IOP) of $30 \mathrm{mmHg}$. She was treated with topical dexamethasone $0.2 \%$ five times daily and acetazolamide $250 \mathrm{mg}$ twice daily. One week after she was asymptomatic, a minimum flare, posterior synechiae and mild lens opacity were then identifiable; gonioscopy showed circumferential iris apposition with diffuse PAS, as shown in Figure 1. One month afterwards, no inflammatory cells were detectable within the

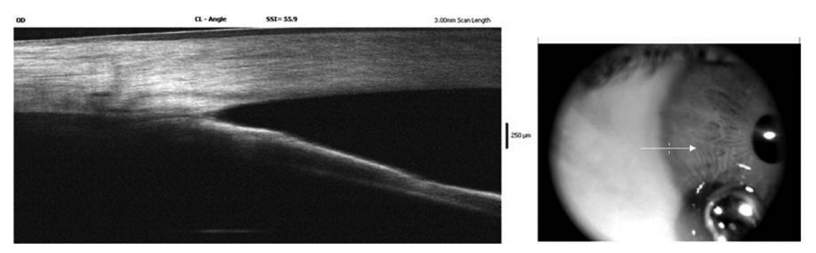

Figure I Anterior segment optical coherence tomography imaging. The picture shows a persisting irido-corneal contact despite central deepening of the anterior chamber during corneal indentation (synechial closure). anterior chamber and the vitreous, IOP was $20 \mathrm{mmHg}$ under treatment (timolol 0.5\% + dorzolamide 2\% twice daily and acetazolamide $250 \mathrm{mg}$ twice daily), and the best corrected visual acuity (BCVA) was 0.8 . The IOP was increasing after discontinuation of the medical treatment, so that four months after the acute episode when the patient was asymptomatic with no redness, flare, keratic precipitates, or other signs of active inflammation detectable, phacoemulsification of the lens was performed. ${ }^{11}$

No complications occurred during surgery, and a posterior chamber intraocular lens was well placed. The patient was prescribed a combination of dexamethasone $0.1 \%+$ netilmicin $0.5 \%$ five times daily. One week after surgery, the visual acuity was excellent (BCVA 1.0). Steroid therapy was then gradually decreased during the following two weeks, at which time a CME developed and the BCVA decreased to 0.4. After four weeks of treatment with topical diclofenac four times daily and acetazolamide $125 \mathrm{mg}$ twice daily, visual acuity completely recovered (BCVA 1.0), no cystoid macular edema was appreciable, and it has not recurred up until now. Figure 2 shows three optical coherence tomographic images demonstrating gradually improving CME.

\section{Discussion}

Two major events have been described in this case report, ie, the occurrence of an unusual inflammatory reaction after ALPI performed for plateau iris syndrome and the onset of cystoid macular edema following phacoemulsification performed on a second occasion in the same eye. Because the occurrence of clinical cystoid macular edema after uncomplicated cataract surgery has a relatively low overall prevalence of less than $3 \%,{ }^{10}$ we postulate that a causative link between acute post-laser iritis and onset of CME existed in our patient. This could be represented by a genetically determined predisposition to overexpression of inflammatory pathways after mechanical or thermal trauma in both the anterior and posterior segments of the eye. ${ }^{12}$

The exact etiological mechanisms leading to CME are not completely understood. ${ }^{13}$ A widely supported theory is that inflammatory mediators released from the anterior segment traverse the vitreous, reach the posterior segment, and disturb the blood-retinal barrier in the macular area, leading to accumulation of intraretinal fluid. ${ }^{14}$ It is known that the iris is a metabolically active tissue able to release inflammatory mediators when injured, ${ }^{15}$ and proinflammatory cytokines have been demonstrated to be released, possibly in different amounts, after both Nd:YAG 

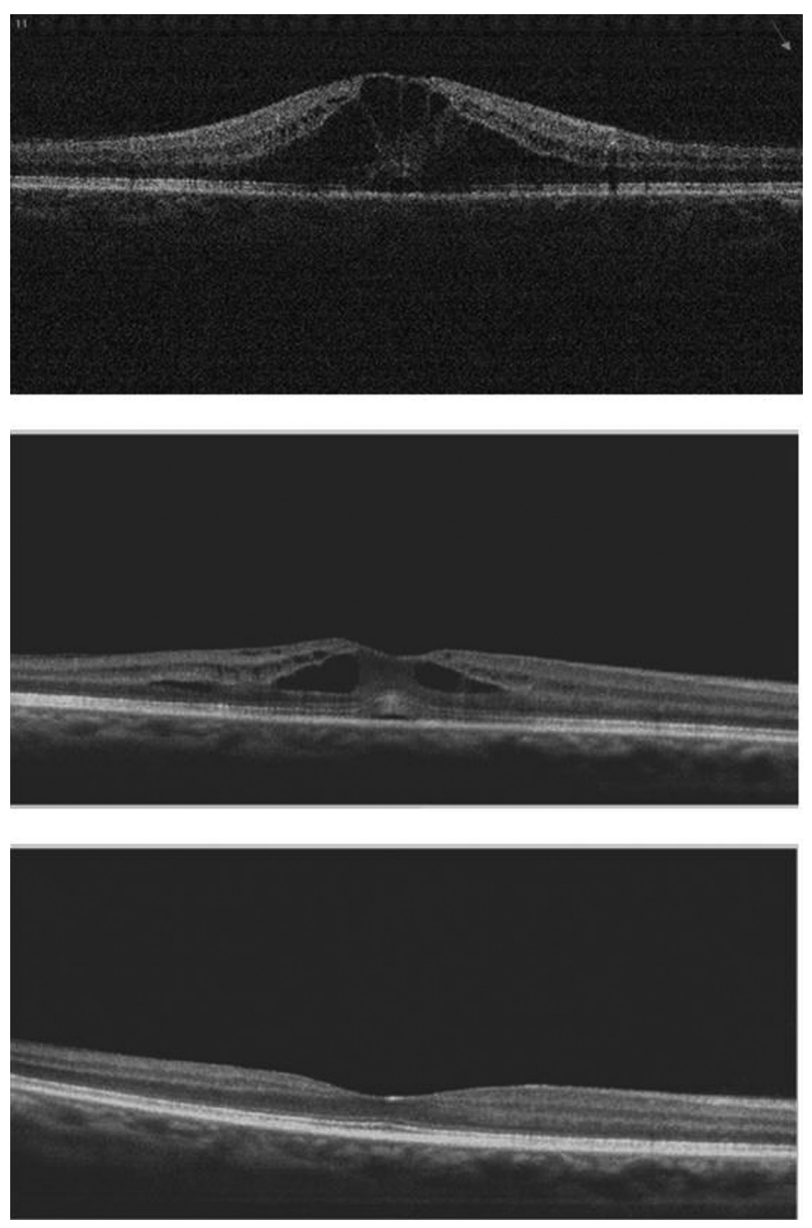

Figure 2 Spectral domain OCT macular images showing the evolution of cystoid macular edema, gradually improving and completely recovering after four weeks (lower picture) of medical treatment.

and argon laser iridotomy. ${ }^{16,17}$ In particular, interleukin-6, prostaglandin $\mathrm{E}_{2}$, and tumor necrosis factor-alpha may accumulate in the aqueous humor after laser application to the iris, ${ }^{16,17}$ leading to the onset of a variable and possibly subclinical inflammation. Cataract surgery could result in intraocular barrier breakdown and diffusion of inflammatory cytokines into the vitreous fluid, thus leading to the development of CME.

Cases of marked inflammation after tapering antiinflammatory steroid therapy following Nd:YAG laser iridotomy have been described, and heavy pigmentation of the iris linked to race has been recognized as a possible predisposing factor. ${ }^{18}$ Similarly, our patient had a dark iris, and this anatomical feature could have played a role in the inflammatory process. To our knowledge, this is the first paper reporting the occurrence of post-ALPI inflammation that was severe and beyond the degree of mild iritis. Moreover, this event has never been proposed as a risk factor for CME. Because no other predisposing conditions were identifiable (ie, chronic uveitis, rheumatologic or autoimmune disorders, diabetes, use of prostaglandin analogs, intraoperative complications), ${ }^{7,15}$ our patient did not receive prophylactic treatment with nonsteroidal anti-inflammatory drugs, and a routine course of topical steroids, but not nonsteroidals, was prescribed after surgery. For this reason, we do not know if use of nonsteroidal antiinflammatory drugs could have prevented the development of CME.

\section{Conclusion}

Based on this case report, a history of severe iritis after laser treatment could represent a predisposing condition for development of CME after cataract surgery. Although further studies are needed to confirm this association, the use of pharmacological agents able to protect against this potentially sight-threatening condition should be considered in such cases. ${ }^{1}$

\section{Disclosure}

The authors report no conflicts of interest in this work.

\section{References}

1. The European Glaucoma Society. Treatment principles and options laser surgery. In: Heijl A, Traverso CE, editors. Terminology and Guidelines for Glaucoma. 3rd ed. Savona, Italy: Dogma SRL; 2008.

2. Polikoff LA, Chanis RA, Toor A, et al. The effect of laser iridotomy on the anterior segment anatomy of patients with plateau iris configuration. J Glaucoma. 2005;14:109-113.

3. The European Glaucoma Society. Classification and terminology primary angle closure. In: Heijl A, Traverso CE, editors. Terminology and Guidelines for Glaucoma. 3rd ed. Savona, Italy: Dogma SRL; 2008.

4. Crouch ER Jr, Lattanzio FA Jr, Williams PB, Mitrev PV, Theobald T, Allen RC. Cyclosporin-augmented laser peripheral iridoplasty. Ophthalmic Surg Lasers Imaging. 2004;35:475-481.

5. Spitzer MS, Ziemssen F, Yoeruek E, Petermeier K, Aisenbrey S, Szurman P. Efficacy of intravitreal bevacizumab in treating postoperative pseudophakic cystoid macula edema. J Cataract Refract Surg. 2008;34:70-75.

6. Rossetti L, Autelitano A. Cystoid macular edema following cataract surgery. Curr Opin Ophthalmol. 2000;11:65-72.

7. Ursell PG, Spalton DJ, Whitcup SM, Nussenblatt RB. Cystoid macula edema after phacoemulsification: Relationship to blood-aqueous barrier damage and visual acuity. J Cataract Refract Surg. 1999;25: 1492-1497.

8. Miyake K, Ibaraki N. Prostaglandins and cystoids macular edema. Surv Ophthalmol. 2002;47:S203-S218.

9. Johnson MW. Etiology and treatment of macular edema. Am J Ophthalmol. 2009;147:11-21.

10. Almeida DR, Johnson D, Hollands H, et al. Effect of prophylactic nonsteroidal antiinflammatory drugs on cystoid macular edema assessed using optical coherence tomography quantification of total macular volume after cataract surgery. J Cataract Refract Surg. 2008;24: 64-69.

11. The European Glaucoma Society. Pathogenetic approach to angle closure. In: Heijl A, Traverso CE, editors. Terminology and Guidelines for Glaucoma. 3rd ed. Savona, Italy: Dogma SRL; 2008. 
12. Sacca SC, Bolognesi C, Battistella A, Bagnis A, Izzotti A. Gene-environment interactions in ocular diseases. Mutat Res. 2009;667: 98-117.

13. Kim A, Stark WJ. Are topical NSAIDs needed for routine cataract surgery? Am J Ophthalmol. 2008;146:483-485.

14. Wittpenn JR, Silverstein S, Heier J, et al; for the Cystoid Macular Edema (ACME) Study Group. A randomized, masked comparison of topical ketorolac $0.4 \%$ plus steroid vs steroid alone in low-risk cataract surgery patients. Am J Ophthalmol. 2008;146:554-560.

15. Gulkilik G, Kocabora S, Taskapili M, Engin G. Cystoid macular edema after phacoemulsification: Risk factors and effect on visual acuity. Can J Ophthalmol. 2006;41:699-703.

16. Er H, Doganay S, Evereklioglu C, et al. Comparison of the effects of argon and neodymium:YAG laser iridotomy on cytokines in the rabbit aqueous humor. Eur J Ophthalmol. 2002;12:183-187.
17. Naveh N, Rosner M, Zborowsky-Gutman L, Rosen N, Weissman C. Comparison of the effects of argon and neodymium:YAG laser iridotomy on prostaglandin E2 and blood-acqueous barrier disruption. Ophthalmic Res. 1990;22:253-258.

18. Siam GA, de Barros DS, Gheith ME, et al. Post-peripheral iridotomy inflammation in patients with dark pigmentation. Ophthalmic Surg Lasers Imaging. 2008;39:49-53.

19. Rossetti L, Chaudhuri J, Dickersin K. Medical prophylaxis and treatment of cystoids macular edema after cataract surgery. The result of a meta-analysis. Ophthalmology. 1998;105:397-405.
Clinical Ophthalmology

\section{Publish your work in this journal}

Clinical Ophthalmology is an international, peer-reviewed journal covering all subspecialties within ophthalmology. Key topics include: Optometry; Visual science; Pharmacology and drug therapy in eye diseases; Basic Sciences; Primary and Secondary eye care; Patient Safety and Quality of Care Improvements. This journal is indexed on

\section{Dovepress}

PubMed Central and CAS, and is the official journal of The Society of Clinical Ophthalmology (SCO). The manuscript management system is completely online and includes a very quick and fair peer-review system, which is all easy to use. Visit http://www.dovepress.com/ testimonials.php to read real quotes from published authors. 